\title{
What does 'Playing Well' mean to elite sports coaches?, implicit thinking of elite Spanish soccer coaches
}

\author{
Sixto González-Víllora ${ }^{1,}$, Jaime Serra-Olivares² ${ }^{2}$ Irene González-Martîi ${ }^{3}$, Andrea \\ Hernández-Martínez ${ }^{4}$ \\ ${ }^{1}$ Facultad de Educación de Cuenca. Universidad de Castilla-La Mancha. Cuenca, Spain \\ \{sixto.gonzalez@uclm.es\} \\ ${ }^{2}$ Facultad de Educación de Albacete. Universidad de Castilla-La Mancha. Albacete, Spain \\ \{jaime.serra@uclm.es\} \\ ${ }^{3}$ Facultad de Educación de Cuenca. Universidad de Castilla-La Mancha. Cuenca, Spain \\ \{irene.gmarti@uclm.es\} \\ ${ }^{4}$ Facultad de Educación de Cuenca. Universidad de Castilla-La Mancha. Cuenca, Spain \\ \{andrea.hernandez@uclm.es\}
}

Received on 22 December 2011; revised on 21 January 2012; accepted on 20 February 2012; published on 15 July 2012

DOI: $10.7821 /$ naer.1.1.27-32

\begin{abstract}
People construct knowledge through a set of highly diverse experiences. Despite being personal, this knowledge is strongly influenced by the specific context where it occurs. Such experience-based knowledge is referred to as 'implicit theories' because it does not fit in with a systematic and theoretical knowledge context like that of scientific knowledge. Coaches work with a number of implicit theories about aspects such as players, competition or training which determine their professional behaviour to a considerable extent. Thirty-nine Spanish First Division coaches were asked the question 'What does playing soccer well mean?' in this study. Their responses were later classified into eight different categories which show the diversity of opinions regarding this matter as well as the possible implicit theories that would guide coaches' actions.
\end{abstract}

KEYWORDS: TEAM SPORTS; ATHLETIC COACHES; CRITICAL THINKING; EVALUATIVE THINKING

\section{INTRODUCTION}

Different people interpret social events in different ways and an understanding of them depends on each individual's knowledge and experience (Nisbett \& Ross, 1980). This gives rise to the notion of implicit theories, which work in the form of representations, the essence of which contributes to a construct made up of experiences that have different natural and socialcultural foundations (Clandinin \& Connelly, 1987; Elbaz, 1991). In this sense, individuals can construct knowledge that is both personally and directly related to the context in which it is produced. This reality has been identified as practical knowledge, professional knowledge (Higgs \& Titchen, 2001), beliefs (Nisbett \& Ross, 1980), and implicit theories. For coaches, these theories are a synthesis of experiences and different cognitions that can guide coaches' decision-making processes and actions. This is why knowledge about coaches' implicit theories of training is of great importance in improving coach education programs (Marrero Acosta, 1992).
An example of how implicit theories would influence the training of two different coaches may look like this. The behavior of one coach, reassured by his natural gift for football as he was an elite player in the past, would hold the implicit assumption that his own abilities place him in a position to develop his own coach duties, as he knows the secrets of football. Another coach, passionate about his job but not a former player, believes in seeking new knowledge with anything that may improve any aspect of his work. The training of the player coach would be hindered by his awareness of his own limitations, as the implicit theories built from the view of the coach are so different from those of a player. The player coach must be conscious of the fact that his professional knowledge will surely suffer from if it is only based on his personal experiences. This implicit theory will lead to repetitive behavior for this kind of coach, limiting any professional development based on reflection. The nonplayer coach holds an implicit theory that his coach development is dependent on constant reflection and acceptance of new knowledge.

Marrero Acosta (1988) defines implicit theories as "a whole of elements and links the activation of which has a certain recurrence as far as they introduce subjects' knowledge (coach knowledge) in a domain of reality (training)." (p. 137). Implicit theories provide a theoretical network for the study of coaches' behavior from a social and cultural perspective of knowledge, as they respond to the essentially practical nature of their singular knowledge. As a matter of fact, most of the coaches' knowledge is made up of experiences which occurred during their practice in different teams. These experiences are unique as they happen in similar but not equal contexts. So, future problems in the training process will be solved by coaches using those resources which were previously useful. This is the way implicit theories are built. However, an implicit theory is not always good in every case, and this is why knowing and putting them in objective terms can help coaches to become more conscious of their own practice and to modify those inadequate or unconscious behaviors. 
Coaches' thinking is strongly influenced by players, matches and the atmosphere in training. Coaches function as subjects who are part of a social context, with a training process intrinsically linked to the limitations and opportunities offered by interaction between individuals (Jones, 2000; Potrac, Brewer, Jones, Armour, \& Hoff, 2000; Potrac \& Jones, 1999; Potrac, Jones, \& Armour, 2002). There is a close relationship between the features of the problems, the motivational attitudes of coaches and their decision-making styles (Chelladurai \& Quek, 1995). Thus, the thought structure of a coach is made up of experiences, values, beliefs and concepts that are organized in explicit or implicit theories and ways of solving problems that lead to an individual teaching style, in contrast to the image of a coach repeating what others did before.

Coaches practical knowledge is therefore generated from practical experience. This practical knowledge is developed by the coach through a search for the connection between theory and practice. It integrates values and beliefs with theories and concepts, and also forms of practical intervention. This knowledge is not only acquired on training courses; informal sources such as one's own experience as a player or the influence of other coaches also play a significant role. Practical knowledge is therefore idiosyncratic, personal, and based on one's own experience (Wade, Coté, \& Mallet, 2006). Its limits are marked out by the characteristics of the context in which one has worked. It is knowledge about practice and based on practice, and it is in this realm where it should be studied (Schempp, 1993). We get the idea of the importance of implicit theories in coaches' behavior from the fact that they appear to have doubts about the content of education courses. They tend not to follow a fixed rule but mainly base their approach on their own experience (Jones, Armour, \& Potrac, 2003; Saury \& Durand, 1998).

Given the importance that implicit theories have in the behavior of coaches, knowing them becomes a highly important part of the process of improving their knowledge. Therefore, we try to provide in this research a descriptive account of the implicit beliefs of elite soccer coaches as to what "playing well" means.

\section{METHOD}

\subsection{Participants}

We set out to find out the implicit theories of elite soccer coaches in Spain. Thirty-nine Spanish League First Division soccer coaches (all males) were interviewed from 2000 to 2006.

\subsection{Procedure}

We start from the hypothesis that the professional coach's accumulated know-how can be a suitable instrument for solving the problems that arise in training and competition, for which coaches use implicit theories based on their personal experience. We carried out this study in order to verify some of the implicit theories present in their work.

A basic notion that should guide the work of coaches is the response to the question what "playing well" means, since training as a whole will be oriented to what every coach believes "playing well" means. The expression "playing well" has a wide meaning, ranging from individual to collective aspects of play.

Only one question was asked: "What does playing soccer well mean?" This single question was chosen because the number of coaches was high and we wanted them to respond freely to the question. Each interview lasted approximately 15 minutes. The interview process began with general information about the purpose of the project and then focused on background and demographic issues (Côté, Salmela, \& Russell, 1995). Following these introductory queries, one open-ended question was asked to elucidate coaches' perceptions of what "playing well" means. The interviews were recorded and transcribed verbatim in order to ensure a comprehensive and accurate record of the information. After meticulous analysis of the data, each interview transcript was checked by every coach to check its accuracy, not only from the point of view of the words spoken but, more importantly, to elicit the meaning of what was expressed (Stake, 1995).

\subsection{Analysis of the Interpretive Interview Data}

The interview transcripts then underwent inductive analysis (Goetz \& Le'Compte, 1984). The objective here was to separate the interview transcripts into segments that represented different beliefs and constructs about what "playing well" means. This process initially involved dividing the text into appropriate pieces of information called 'meaning units' (Tesch, 1990). We have not taken into account the quality of coaches' responses, because they can all be important in demonstrating the beliefs of coaches. Once this step had been completed, common features between meaning units were identified. This procedure, referred to as 'creating categories,' involved collating meaning units and organizing them into distinct groupings that were known as 'properties' (Côté, Salmela, Baria, \& Russell, 1993). Three researchers identified categories independently and the results were then compared. Following this step, the data analyses proceeded to a higher level of interpretation, which consisted of comparing properties to organize them into larger and more embracing categories (Côté et al., 1995). The respondents gave permission for their answers to be published, together with their real names. Table 1 shows the emerging categories and frequencies.

Table 1. Categories and frequencies

\begin{tabular}{lc}
\hline Categories and subcategories & Frequency \\
\hline 1.Group order or organization & 27 \\
1.1.Balance between defense and attack & 9 \\
1.2. Good organization, group harmony: the eleven players work as & \\
$\quad \begin{array}{l}\text { a group, are well positioned on the pitch. Team play above } \\
\text { individualities }\end{array}$ & 12 \\
1.3.As before, adding individual and group talent & 4 \\
1.4.Balance between defense, attack and counter-attack & 2 \\
\hline 2.Winning, getting a good result & 23 \\
2.1.Winning; being better than the opponent & 7 \\
2.2. Winning above all: searching for efficiency, understood as the & 15 \\
pursuit of victory & 1 \\
2.3.Taking into account the level of the club & 19 \\
\hline 3.Emphasis on preparation or training & \\
3.1.Daily training (microcycle): carry out what is practiced during \\
the week in the match, achieving the objectives set for the short \\
term
\end{tabular}


Table 1. (Continued...)

\begin{tabular}{lc}
\hline Categories and subcategories & Frequency \\
\hline $\begin{array}{l}\text { 4.3.Technical-tactic domination, there is no need for spectacular } \\
\text { actions }\end{array}$ & 6 \\
\hline $\begin{array}{l}\text { 5.Emphasis on attack } \\
\text { 5.1.Emphasis on attacking play, you have to defend but the most } \\
\text { important thing is attacking }\end{array}$ & 8 \\
\hline $\begin{array}{l}\text { 6.Making the right decisions } \\
\text { 6.1. Making the right decision at any given time, interpreting play } \\
\text { in a way that the opponent cannot anticipate }\end{array}$ & 6 \\
\hline $\begin{array}{l}\text { 7.Enjoyment } \\
\text { 7.1. What we like is the way the team plays. That the team should } \\
\text { play attractive soccer }\end{array}$ & 6 \\
7.2. It is only enjoyable if we win & 4 \\
\hline $\begin{array}{l}\text { 8. It is not possible to define what 'play well' means } \\
\text { 8.1. There are many ways of playing well, the game is very plural, } \\
\text { everyone interprets it in a different way }\end{array}$ & 3 \\
\hline
\end{tabular}

\section{RESULTS}

\subsection{Group organization and group equilibrium}

This is the category that received most responses within the definitions given for playing soccer well (category 1). The majority of the coaches interviewed support this statement (twenty-seven of the thirty-nine were in agreement with it), divided into three themes, "Balance between defense and attack" (subcategory 1.1.), "Be well organized, group harmony" (subcategory 1.2.), "Equal to one of the above, adding individual talent to the group" (subcategory 1.3.) and "Balance between defense, counter-attack and attack" (subcategory 1.4.).

Some coaches think that two basic factors are required for this group organization (i.e., defensive and offensive phases). In the words of Preciado Rebolledo:

Soccer has two facets: when you have the ball and when the other team has the ball. Each is as important as the other. In Spain we do not give too much consideration to the level of skill when we do not have the ball.

For many people, this occurs in practice through actual team play. Sacristán Mena says that, in order to express what playing well means:

You have to think on the general level, the team level. Playing well is playing as a team. On the pitch the team should try to reach a level of play that allows it to beat the opposing team. I think that this is playing well, above individualities, because soccer is a team game and what matters is that a team should extract a good performance from its way of playing, and beat the other team through that way of playing.

Many coaches believe that the organization of the group and having a common objective are necessary in order to play soccer well. Aguirre Onaindía says that playing well is "having eleven wills aiming at the same objective" while Olabe Aranzábal considers that "you need all the players in your team together around a common idea and objective".

Some coaches believe individual talent needs to be added to team play in a situation where the balance between the different lines of players and technical-tactical positions are vital for harmony of play. Caparrós Camino says that:

I would highlight two aspects: playing the game well and playing the ball well. The first means playing well as a group, that each player knows what his teammate is going to do, both when attacking and defending. The second is that each player functions correctly, with good technique, on an individual level.

\subsection{Winning, getting a good result}

This is the second most mentioned category, with twenty-three responses from the thirty-nine coaches consulted, mainly due to the importance of the subcategory "Winning above all: searching for efficiency, understood as the pursuit of victory" (subcategory 2.2.). Other subcategories were "Winning: playing better than the opponent" (subcategory 2.1.) and "Taking into account the level of the club" (subcategory 2.3.).

For some coaches playing well is equivalent to winning or getting a good result. Herrera Lorenzo says that playing well is "winning the match; that is the most realistic approach. From there, we can add anything else we want". On this particular point Salvadores Canedo argues that there is a problem in modern soccer: the result as the validator of good play. One reads, hears and observes -also from coaches- that the result of the match will indicate if the play has been good or not. This can be valid, to a certain extent, in the case of teams with very similar potential, but it does not serve as a general rule at all. This opinion is supported by Kresic Juric, who says: "one thing is for Real Madrid to play well, for example, but for a Third Division team to play well is something different".

\subsection{Emphasis on preparation or training}

The third-placed preference of the coaches regarding playing well is the emphasis on preparation or training, answered by nineteen of the coaches. It has five contributions in the subcategories "Daily training (microcycle)" (subcategory 3.1.), "Having an identity" (subcategory 3.2), "Emphasis on physical preparation" (subcategory 3.3.), "Emphasis on psychological preparation" (subcategory 3.4.)" and "Taking advantage of the weak points or limitations of the opponent and minimizing its strong points" (subcategory 3.5.).

Efforts are made to fulfill specific and real objectives that lead to the best possible play in the long term (3.1. Daily Training (microcycle) to carry out in the match what is practiced during the week, to achieve short-term objectives). Ferrando Giménez says: "it is when the match is finished that we should check that everything we worked on during the week has been put into practice".

Some of these implicit theories highlight long-term preparation in order to achieve objectives in a competition or throughout a season (subcategory 3.2. Having an identity, adding long-term preparation). Miñano Espín says that it is a question of "having our own identity and a sufficiently dynamic pattern of play to be able to overcome all the difficulties that top-flight competition involves".

In the area of training the authors put more or less emphasis on particular questions, and these can correspond to physical condition and its application in matches: resistance, speed, strength, power, etc. (3.3. Emphasis on physical preparation: running hard, speed, physical intensity...). Ferrando Giménez believes that "if we play with precision and we add speed I think we are close to the ideal". In other words, he considers that there are two fundamental factors during play: technique and physical condition.

Other coaches go further. In addition to the training factors mentioned they include psychological preparation as a factor of vital interest, in terms of motivation, goals to be achieved, and self-esteem (3.4. Emphasis on psychological preparation). We 
include the claims of two coaches as clear exponents of these ideas, the first being Argibay Pazos, who says: "there are three fundamental factors: organization (the balance between attack and defense), intensity (physical and mental, that allows me to control the pace of the game and win it in the details) and mentality (it will be difficult to win if I do not instill victoryseeking attitudes)". Manzano Ballesteros says that: "it is putting into practice on the pitch a dynamic compensation of the elements that define soccer: technical, tactical, physical and psychological elements. This harmonious, well-balanced compensation will make the team play well".

Finally, subcategory 3.5. "Taking advantage of the weak points or limitations of the opponent and minimizing its strong points. Emphasizing what our team is better at than the opponent", means taking advantage of weak points or limitations of the other team and cancelling out, as far as possible, its strong points. Salvadores Canedo understands playing well to be "the use of the technical and tactical resources of our team to restrict the attacks of the other team and impose ours". Or, as Esnal Pardo explains more explicitly: "If, in principle, we know we have certain better qualities than the opponent, we need to try and take advantage of them. The ideal situation is to master all soccer techniques and tactics". Training thus becomes an essential element in preparation for competition.

\subsection{Technical and tactical mastery}

This category is found in fourteen of the coaches responses, which are distributed in a similar fashion among its three subcategories: "Linking technique with tactics, but with technical emphasis by the player" (subcategory 4.1.), "Performing beautiful technical actions with practical sense" (subcategory 4.2.) and "Technical-tactical mastery, without the need for spectacular actions" (subcategory 4.3.).

The first of these subcategories emphasizes technique in play (4.1. Linking technique with tactics: technical emphasis of the player). This aspect of play is essential for the defenders of this implicit theory. Players need to master technique before they can master their sense of time, space and tactics. The speed of moves needs to be adjusted on the basis of efficiency criteria at any given time. This idea is corroborated by Conde Moldes when he says that "Technique is extremely important in soccer. If a player develops his technique he will be less dependent on the ball and will have more time to work out what is happening in the match. Technical quality (speed plus precision plus the best choice) certifies the efficiency of tactics".

The next two subcategories are opposite and create a dichotomy between soccer professionals. Some say that playing well is playing attractive soccer, and performing spectacular technical actions that are not usually seen in stadia. Muñoz Manrique bases this idea on the professional soccer player, because "the aim is to win and play attractive soccer". Others believe that playing well is restricted to aspects such as organization, the balance between the lines of the team, aiming at objectives, and so forth, but it is not necessary to carry out spectacular actions. In this sense Kresic Juric claims that playing well "is efficiently implementing all the aspects that play requires. One thing is playing brilliantly but playing well is something else. It is a question of having very clear ideas and carrying them out well for ninety minutes or almost all the match".

\subsection{Emphasis on attack}

Only eight coaches consider "emphasis on attack" as a defining element of good play. An example of the importance given to attack and the absence of the defense factor could be reflected in the words of Pérez García who says that playing well "is not just holding the ball, 'nutmegging' opponents or being flashy". Playing well involves playing on a team and individual level when circumstances require, moving the ball intelligently and at the pace required at any given moment". The prevalence of attack over defense is highlighted in other statements, as in the case of Maturana García, who claims that playing well "starts when the fans react. When the fans applaud that means the team or a player is playing well. Using attack and defense correctly, but attacking more often than defending". Sánchez Martín supports this idea of playing well and stated:

Related to attacking soccer, a team is playing well when it is attacking. Playing soccer well is enjoying oneself, dribbling well, shooting at goal with accuracy... Basically, we have to control the match. It also includes defending well when we do not have the ball, although that is for the professionals. The important thing for the fans is that we have the ball and make good moves.

\subsection{Making the right decisions}

This category received only six responses. Making the right decision implies choosing the best move at any given time. In reply to the question "What does playing well mean?", Giráldez Díaz says "doing the right thing at each moment. It could be nutmegging an opponent or thumping the ball into the stands. It all depends on the situation. As simple as that". Buceta says this on the same subject:

It is taking the best decisions on the basis of the circumstances; in other words, the decisions that cause most problems to the opponent in each situation, which therefore increases your own options. These decisions, although they may be simple, reflect the tactical intelligence of the players and the good work of the team.

\subsection{Enjoyment}

This category also received six responses. Importance is given to enjoying the game, feeling good about the moves made, leaving the field happy with what has been seen and done during the match. Maturana García concludes that playing well "starts with the fans' acceptance, when the fans start applauding that is when you are playing well. Using attack and defense correctly, but attacking more often than defending". In the same direction, Ferrando Giménez says:

Good play means that I like the way the team has played. As a spectator, playing well means we are happy with what we have seen [...]. If we have won, well, all the better, because we should not forget that we work towards winning.

Other professionals say that if the team does not win or get a good result the match is not enjoyable, which is reflected from subcategory 2.2. "Winning above all" and category 7 "Enjoyment", then generating subcategory 7.2. "It is only enjoyable if we win." An example of this would be the definition given by Yepes Peñas: "Playing well is winning and playing attractive soccer". 


\subsection{It is not possible to define what "playing well" is}

Only three coaches refer to this category. At first sight, it seems to be a category that contradicts this study, but if we look more closely we will see that this is not the case. Indeed, there is a wide range of opinions about the meaning of "playing well", with some claiming that "it is a concept or definition that cannot be marked out", although those who support it try and rectify their answer later. This is the case of Etxarri Sariaín, who answers the question in the following way:

This is very complex. I would say that one of the most attractive elements in soccer is the variety of ideas and emotions [...]. You cannot say what "playing well" is because there are many forms of play and everyone has their own idea of interpreting and experiencing soccer. As a result, I would say that playing well is achieving the objective set in advance.

\section{DISCUSSION}

In the light of the large number of categories that emerge, we can confirm the great variety of answers around what "playing well" means. We can equally confirm the intuitive nature of knowledge on the matter, which seems to be based more on personal experience than on a systematic method (Nisbett \& Ross, 1980). Their personal experience makes coaches underline specific characteristics of the game that have perhaps been a key to success for them. However, a deep analysis of the categories as a whole and the frequency of coaches opinions about them give us a different view of the situation.

In fact, good organization, team play above individualities, or the contribution of individual talent to the group are elements that make up "playing well" from the point of view of professionals. The primacy of group aspects over individual aspects is evident, and as Potrac et al. (2002) indicate, the construction of the team is the key to success. Therefore, the main objective is to create successful teams, with the individual development of the players a secondary consideration. In this sense, Mombaerts (2000) claims:

High-level soccer can only be conceived on the basis of a cohesive and structured team whose organizational principles depend on the skills of each player. Organized and creative play is based on the constant search for balance between defense and attack during several phases of play (p. 18).

Gréhaigne (2001) also establishes that it is necessary to move from an individual to a collective approach in the organizational framework. The player should really fit into a group in his personal actions, giving the best of himself to the group.

The second most quoted element in "playing well" is winning or getting a good result. We are faced with an implicit theory that has little to do with a rigorous response to the problem posed, but more to do with the coach keeping his job than with any other consideration of a scientific nature. Many coaches in the Spanish First Division are sacked when the team obtains poor results and/or is in a low position in the League. Therefore, winning every match without worrying about the quality of the team's play is more important, which is why efficiency in terms of winning matches is more important for the coach and therefore seen as "playing well". Indeed, a sustained level of stress due to criticism from board members, the media and the fans is a decisive factor in the behavior of the coach; burnout in coaches is not uncommon (García Ucha, 2000). This simply confirms that the coach's context is a determining factor in the implicit theories that will condition his decisions in the course of his work (Clandinin \& Connelly, 1987).

A large number of coaches see training sessions as the right instrument to be able to "play well." They consider training as a complex phenomenon that needs to cover physical and psychological factors and others related to technique and tactics, etc. This opinion ties in with the notion of sporting excellence expressed by Orlick (2000), in which commitment means a motivational level of active and long-lasting commitment to getting to a level of "playing well".

The fourth response by the coach has to do with "technical/tactical skill," which some coaches call "skilled performance." It is often debated whether this is innate or can be learned through the right kind of training (Williams \& Hodges, 2005). In this respect, the behavior of players shows a constant tension between knowledge and action, so players need to be able to organize their actions based on context in order to be able to understand the game. Hence, players should be able to show mastery of different practice scenarios, and combining information with movement should undoubtedly be one objective of training (Savelsbergh \& Van Der Kamp, 2005).

Other categories are mentioned less, for example, relating "playing well" to putting "emphasis on attack" during play and thereby trying to gain admiration and applause from the fans through spectacular soccer, which are basically determining factors arising from the context that has an influence on the coach (Jones, 2000; Potrac et al., 2000).

Some coaches associate "playing well" with "making the right decisions." However, it is rather restrictive to associate taking the right decisions individually with the perfect functioning of the team because, as has been said, if each player does what is rational for him it may be detrimental to the team as a group (García-Mas \& Vicens, 1995). Therefore, the decision to not cooperate with the team through effort can be perfectly rational from the point of view of an egoistic player who prefers to save his strength, as is explained in the now classical formulation of the prisoner's dilemma (Scodel \& Minas, 1960). Therefore, "making the right decisions" is a vague notion that can only be explained by the previous experience of the coach (Potrac \& Jones, 1999; Potrac et al., 2002).

The penultimate category considers that "playing well" consists of enjoying the sport and each match; indeed, there are so few responses that it can be considered almost marginal. This approach has to do with the already-expressed notion that attributes sporting success to the spontaneity and efficacy of the players. This belief puts the emphasis on confidence in the player, considered individually above the group (Frauda Uriondo, 1999), with a consequent negative influence on the concept of the training process. It satisfies the fans and the players themselves through play that takes place independently of its real and objective evaluation.

Finally, there is a category that denies the possibility of determining a reason for playing well, which brings us back to the premises put forward by Nisbett and Ross (1980) relating to the need to understand people's knowledge on the basis of their personal experience. Indeed, coaches who believe that it is impossible to define a reason for "playing well" attribute this to the complexity of the elements that intervene in the process. This has devastating effects, because given that it is impossible to know it, it is a waste of time studying it, which leads to a lack 
of interest in the subject and associated effects on the objectives and the methodology of training.

\section{PRACTICAL APPLICATION}

From the results obtained in this article, and their consequent discussion, it can be deduced that coaches in this study seem to handle a limited range of concepts or ideas in the form of implicit theories regarding what it means to play well. Coaches should analyze their own implicit theories to manage the reasons from which decisions are made from technical, tactical, physical or psychological perspectives. Such reflection would allow the coach to see if their actions are appropriately based on personal beliefs. Coaches would eventually become more successful in their professional development, as they would be able to put aside their not-evolving tendencies in their training methods.

The possible implicit theories coaches apply in their coaching actions make them reject some strategies over others. Coaches do not use strategies that are not part of their repertoire, as they are not based on their personal experience. Therefore, coaches should analyze their own implicit theories from a critical point of view, so they are able to use psychological, sociological or physical tools to improve players training, interacting with their families or treating levels of anxiety, for example, when young athletes need it. Consequently, that critical revision of implicit theories would be and extraordinary evolution of their training methods.

\section{CONCLUSIONS}

We can draw the following conclusion: "Playing well" is an extraordinarily complex notion that includes a limited number of categories, from considering good play as victory to denying the possibility of knowing which the essential elements of "playing well" are, going through a number of other variables which have different meanings for different coaches. This is why knowing and describing with objective terms coaches implicit theories is a basic step in their education and professional development.

\section{REFERENCES}

Clandinin, D. J., \& Connelly, F. M. (1987). Teachers' personal knowledge. What counts as personal in studies of the personal. Journal of Curriculum Studies, 19(6), 487-500. doi: 10.1080/0022027870190602

Côté, J., Salmela, J. H., Baria, A., \& Russell, S. J. (1993). Organising and interpreting unstructured qualitative data. The Sport Psychologist, 7(2), 127-137.

Côté, J., Salmela, J. H., \& Russell, S. (1995). The knowledge of high performance gymnastic coaches: competition and training considerations. The Sport Psychologist, 9(1), 76-95.

Chelladurai, P., \& Quek, C. B. (1995). Decision style choices of high school basketball coaches: The effects of situational and coach characteristics. Journal of Sport Behaviour, 8(2), 91-108.

Elbaz, F. (1991). Research on the teacher's knowledge: the evolution of a discourse. Journal of Curriculum Studies, 23(1), 1-20. doi: 10.1080/0022027910230101

Frauda Uriondo, L. (1999). La visión de juego en el futbolista. Barcelona: Paidotribo.

García-Mas, A., \& Vicens, P. (1995). Cooperación y rendimiento en un equipo deportivo. Psicothema, 7(1), 5-19. Retrieved from http://www.psicothema.com/pdf/952.pdf

García Ucha, F. (2000). Entrenadores y burnout [Electronic Version]. Lecturas: Educación Física y Deportes, 28. Retrieved from http://www.efdeportes.com/efd28/burnout1.htm

Goetz, J., \& Le'Compte, M. (1984). Ethnography and Qualitative Design in Educational Research. New York: Academic Press.

Gréhaigne, J. F. (2001). La organización del juego en el fútbol. Barcelona: INDE.
Higgs, J., \& Titchen, A. (2001). Practice knowledge \& Expertise in Health Professions. Oxford: Butterworth-Heinemann.

Jones, R. L. (2000). Toward a sociology of coaching. In R. L. Jones \& K. M. Armour (Eds.), The Sociology of Sport: Theory and Practice (pp. 33-43). London: Wesley Longman.

Jones, R. L., Armour, K., \& Potrac, P. (2003). Constructing expert knowledge: The case of a top-level proffesional soccer coach. Sport, Education and Society, 8(2), 213-229. doi: 10.1080/13573320309254

Marrero Acosta, J. (1988). Las teorías implícitas y la planificación de la enseñanza. In C. Marcelo García (Ed.), Avances en el estudio sobre el pensamiento de los profesores (pp. 135-144). Sevilla: Servicio de Publicaciones de la Universidad de Sevilla.

Marrero Acosta, J. (1992). Las teorías implícitas del profesorado: Un puente entre la cultura y la práctica de la enseñanza. In A. Estebaranz García \& V. Sánchez García (Eds.), Pensamiento de Profesores y Desarrollo profesional (Vol. 1). Sevilla: Universidad de Sevilla.

Mombaerts, É. (2000). Fútbol. Del análisis del juego a la formación del jugador. Barcelona: Inde.

Nisbett, R. E., \& Ross, L. (1980). Human inference: Strategies and short coming of social judgment. Englewood Cliffs, NJ: Prentice Hall.

Orlick, T. (2000). In Pursuit of Excellence: How to Win in Sport and Life Through Mental Training (3rd ed.). Champaign, IL: Human Kinetics.

Potrac, P., \& Jones, R. L. (1999). The invisible ingredient in coaching knowledge: a case for recognizing and researching the social component [Electronic Version]. Sociology of Sport Online, 2(1). Retrieved from http://physed.otago.ac.nz/sosol/v2i1/v2i1.htm

Potrac, P., Brewer, C., Jones, R. L., Armour, K. M., \& Hoff, J. (2000) Toward an holistic understanding of the coaching process. Quest, 52(22), 186-199.

Potrac, P., Jones, R. L., \& Armour, K. M. (2002). "It's all about getting respect": The coaching behaviors of an expert English soccer coach. Sport, Education and Society, 7(2), 183-202. doi: 10.1080/1357332022000018869

Saury, J., \& Durand, M. (1998). Practical knowledge in expert coaches: On-site study of coaching in sailing. Research Quarterly for Exercise and Sport, 69(3), 254-266.

Savelsbergh, G., \& Van Der Kamp, J. (2005). A especificidade da prática: o fútbol como ejemplo. In D. Aráujo (Ed.), $O$ contexto da deciçao. A acçao táctica no desporto (pp. 391-395). Lisboa: Visão e Contextos.

Scodel, A., \& Minas, J. S. (1960). The behavior of prisoners in a "Prisioner's Dilemma Game". The Journal of Psycology, 50(1), 133138. doi: 10.1080/00223980.1960.9916429

Schempp, P. (1993). Constructing professional knowledge: A case study of an experienced high school teacher. Journal of Teaching in Physical Education, 13(1), 2-23. Retrieved from http://journals.humankinetics.com/AcuCustom/SiteName/Documents /DocumentItem/9936.pdf

Stake, R. (1995). The Art of Case Study Research (2nd ed.). London: Sage.

Tesch, R. (1990). Qualitative Research Analysis Types and Software Tools. Philadelphia: RoutledgeFarmer.

Wade, G., Coté, J., \& Mallet, C. (2006). Developmental paths and activities of successful sport coaches. International Journal of Sports Science \& Coaching, 1(1), 69-76.

Williams, A. M., \& Hodges, N. (2005). Practice, instruction and skill acquisition in soccer: Challenging tradition. Journal of Sports Sciences, 23(6), 637-651. doi: 10.1080/02640410400021328 